\title{
Polymorphisms of endothelial nitric oxide synthase and hypoxia-inducible factor 1 alpha genes play a role in susceptibility to coronary artery disease
}

\author{
Ali Asghar Kiani ${ }^{1,2}$, Vahide Heydari Nazarabad ${ }^{1}$, Kolsoum Ahmadi ${ }^{1}$, Khatereh Anbari ${ }^{3}$, Babak Baharvand \\ Ahmadi ${ }^{4}, *$
}

${ }^{1}$ Razi Herbal Medicines Research Center, Lorestan University of Medical Sciences, Khorramabad, Iran

${ }^{2}$ Department of Hematology and Blood Transfusion, school of Allied Medical sciences, Lorestan University of Medical Sciences, Khorramabad, Iran

${ }^{3}$ Department of Social Medicine, school of Medicine, Lorestan University of Medical Sciences, Khorramabad, Iran

${ }^{4}$ Department of Cardiology, school of Medicine, Lorestan University of Medical Sciences, Khorramabad, Iran

Correspondence

Babak Baharvand Ahmadi, Department of Cardiology, school of Medicine, Lorestan University of Medical Sciences, Khorramabad, Iran

Email: bbaharvandba@gmail.com

History

- Received: 16 July 2018

- Accepted: 10 September 2018

- Published: 29 September 2018

DOI :

https://doi.org/10.15419/bmrat.v5i9.480

\section{Check for updates}

\section{Copyright}

(c) Biomedpress. This is an openaccess article distributed under the terms of the Creative Commons Attribution 4.0 International license.

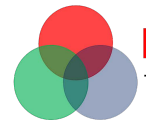

\begin{abstract}
Objective: Genetics is a known factor in the suscepibility to cardiovascular disease. In this study, polymorphisms of endothelial nitric oxide synthase (eNOS) (T876C and G894T) and hypoxiainducible factor 1 (HIF1) (rs10873142 and rs41508050) in coronary artery disease were compared with healthy subjects, and the relationship between these mutations and risk of coronary artery disease (CAD) was assessed. Methods: Blood samples were collected from 138 patients with obstructive $C A D$ and 115 healthy subjects. Polymerase chain reaction- restriction fragment length polymorphism (PCR-RFLP), Griess test, and enzyme-linked immunosorbent assay (ELISA) were used to measure serum nitric oxide (NO) and paraoxonase antioxidant. Independent t-test was used to examine the relationship between variables. Results: There was no significant difference between genotype frequency in healthy subjects and patients for eNOS and HIF1 $\alpha$ polymorphisms. There was no significant difference between these polymorphisms and age, sex, hypertension and lipidemia. Furthermore, the difference in mean serum levels of NO in different genotypes of the G894T gene was not significant between the patient and control groups. However, the difference in mean serum NO levels in different genotypes of the T786C gene was significant between the patient and control groups such that minimum and maximum serum $\mathrm{NO}$ levels were observed in individuals bearing TT and TC genotypes, respectively. The difference in mean serum NO levels was higher in patients than in controls, and was statistically significant. Conclusions: The results suggest that the T876C polymorphism could be associated with low serum NO level and implicated as a risk factor for developing CAD. Furthermore, our findings indicate that genetics may not be involved in susceptibility to CAD; however, further comprehensive studies are required.

Key words: Coronary artery disease, eNOS, HIF1 $\alpha$, Polymorphism
\end{abstract}

\section{INTRODUCTION}

Cardiovascular diseases, especially coronary artery disease (CAD), are a major cause of death worldwide. CAD is a complex, multi-factorial and polygenic disease caused by atherosclerotic plaques in coronary artery walls. Generally, hypertension, hypercholesterolemia, smoking and diabetes are known as the main risk factors for cardiovascular disease. However, less than $10 \%$ of men with chronic heart disease have three or four risk factors concurrently and over $60 \%$ of cases have no or only one risk factor. On the other hand, some people with these risk factors lack cardiovascular complications. Therefore, genetics should also be considered as another important risk factor associated with cardiovascular complications. The role of genetics in cardiac disorders has long been unclear but recent studies indicate 45 hereditary factors predisposing to cardiovascular diseases ${ }^{1}$.

Many studies suggest an equal contribution of genetic and environmental factors to the development of cardiovascular diseases and some researchers state that genetics plays the role of the trigger and environmental factors as shooting the gun ${ }^{2}$. Hence, the results of investigations addressing real contribution of genetics are not conclusive, prompting us to study the role of genetics in the development of CAD in the almost genetically untouched Lorestan Province in the west of Iran. Given the fact that the rate of immigration to this province has been low and inhabited almost entirely by indigenous people, we hypothesized that our analysis would yield results different from studies conducted in Iran and worldwide. Indeed, our previous study in this province showed a significant difference in the prevalence of beta globin gene mutations in patients with thalassemia major in the Lorestan Province compared with that in most global investigations $^{3}$.

In the present research, we selected two genes of the 
antioxidant system which are effective on the cardiovascular system; the genes are hypoxia-inducible factor 1 alpha (HIF $1 \alpha)$ and endothelial nitric oxide synthase (eNOS). The effects of important polymorphisms of these genes, such as $\mathrm{C}>\mathrm{T}$ (rs10873142) and SNP: p.T4181 (rs41508050) in the HIF gene, as well as T786C and G894T in the eNOS gene, were studied in CAD patients.

Given the protective role of NO against important atherogenesis events, eNOS gene has gained considerable importance in the pathogenesis of coronary heart disease. Nitric oxide is a free radical and the most powerful vasodilator ever known. It plays an important role in the regulation of several physiological functions, including vascular activity, immunologic function, platelet aggregation inhibition, and limited low-density lipoprotein (LDL) oxidation ${ }^{4}$. T786C polymorphism causes an approximately $50 \%$ reduction in eNOS gene promoter activity and substitution in exon 7 at codon 298 is associated with enzyme dysfunction $^{5}$. Several studies have reported the correlation between polymorphisms of oxidative genes, such as HIF $1 \alpha$ and eNOS, with $\mathrm{CAD}^{6}$ as well as the interaction of eNOS gene polymorphisms in CAD with serum NO levels ${ }^{7}$.

HIF1 acts as a regulator of oxygen homeostasis. It plays an important role in atherosclerosis pathology through activation of several key genes involved in angiogenesis, energy metabolism, apoptosis/proliferation response, and vasomotor function ${ }^{6}$. In fact, acute ischemic injury due to lack of oxygen homeostasis has been implicated in CAD pathogenesis. Disrupted balance in oxygen supply and demand is a function of reduced blood flow due to atherosclerotic plaque formation and inflammatory processes within the vascular endothelium ${ }^{8}$.

In the study by Chen et al., HIF1 $\alpha$ over-expression as well as correlation between HIF1 $\alpha$ levels and severity of atherosclerosis have been reported ${ }^{9}$. Interestingly, polymorphisms can regulate the expression, structure and stability of HIF $1 \alpha$ mRNA or protein ${ }^{10}$. Furthermore, eNOS is among the downstream target genes directly regulated by HIF $1 \alpha^{11}$, and is one of the three enzymatic isoforms which converts $\mathrm{L}$-arginine to $\mathrm{L}$ citrulline leading to NO synthesis ${ }^{12}$.

The aim of the present study was to assess the impact of C>T (rs10873142) and p.T4181 SNP: (rs41508050) polymorphisms in the HIF gene as well as the T786C and G894T polymorphisms in the eNOS gene with regards to CAD susceptibility. Moreover, we aimed to study the relationship between different genotypes of T786C and G894T polymorphisms with concentrations of $\mathrm{NO}$, and the difference in serum levels of NO and PON in the patient and control groups in Lorestan Province, Iran. The reason for choosing these mutations was that they had the highest association with heart disease in previous studies.

\section{METHODS}

\section{Subjects}

This study was conducted in the Lorestan Province of Iran on 138 unrelated patients with CAD and 115 unrelated healthy subjects, from 2013 to 2015 . Informed consent was obtained from patients and controls, and the study was approved by the Ethical Committee of Lorestan University of Medical Sciences. Patients supposedly with a history of CAD were referred to the angiography ward of the Cardiovascular Center at Shahid Madani Hospital in Khorramabad for further confirmation. Patients with established CAD were enrolled in the study. Healthy subjects were also enrolled after eligibility confirmation thorough examination.

The known risk factors for CAD are high blood pressure ( $\geq 90 / 140 \mathrm{~mm} \mathrm{Hg}$ ), diabetes mellitus (fasting glucose above $120 \mathrm{mg} / \mathrm{dL}$ or before treatment), family history of CAD, and smoking. These factors were assessed in both healthy subjects and patients. The case group included 73 men and 65 women with mean age of $61.53 \pm 10.43$ years, and the control group included 60 women and 55 men with mean age of $54.33 \pm 13.41$ years.

\section{Phlebotomy}

For genetic studies and measurement of serum biochemical parameters, venous blood samples were collected in the morning after overnight fasting and stored in EDTA-containing vials at $4^{\circ} \mathrm{C}$. The vials were then centrifuged at $3500 \mathrm{rpm}$ for 5 minutes and separated serum samples were kept at $-80^{\circ} \mathrm{C}$. The Geno Plus Genomic DNA Extraction Midiprep System (Viogene, Taiwan) was used for DNA extraction from blood samples, according to the manufacturer's instructions.

\section{Biochemical analysis}

Serum NO level was determined by Griess method ${ }^{13}$. Serum paraoxonase (PON1) level was measured using Human PON1 enzyme-linked immunosorbent assay (ELISA) Kit (Glory Science Co., Ltd, TX, USA) according to the kit protocol.

\section{DNA analysis}

We used polymerase chain reaction- restriction fragment length polymorphism (PCR-RFLP) technique 
to detect different SNP alleles and genotypes. The primer sequences, PCR conditions, and restriction enzymes (Fermentas) are summarized in Table $1^{14,15}$. The digestion products were then run on a $2 \%$ agarose gel and stained with safe stain.

\section{Statistical analysis}

SPSS version 18 was used for statistical analysis. The Hardy-Weinberg equilibrium for frequency of genotypes and characteristics of the subjects was reported with chi-square test. We used Fisher's exact test and odds ratio (OD) with 95\% confidence interval (CI) to calculate the association between $\mathrm{CAD}$ and the genetic polymorphisms. NO and PON1 concentrations were expressed as mean $\pm \mathrm{SD}$. Mean concentrations of PON1 and NO in serum, as well as NO concentrations of the different genotypes, were compared via analysis of variance (ANOVA) and t-tests. $\mathrm{P}<0.05$ was considered statistically significant.

\section{RESULTS}

Digestion of wild-type and polymorphic DNA yields fragments which are shown in Figures 1, 2, 3 and 4.

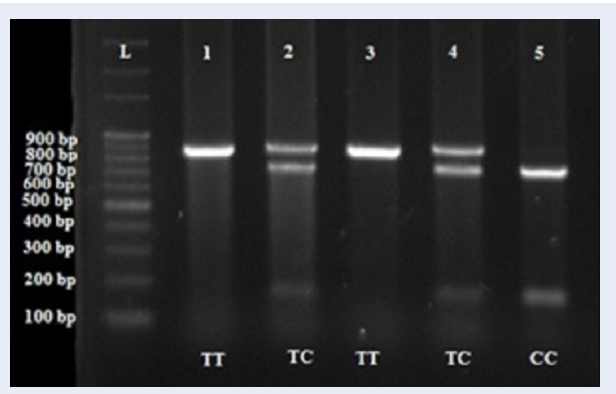

Figure 1: Analysis of polymorphism in HIF-1a using PCR followed by specific restriction enzyme digestion. SNP of HIF-1a C>T (rs10873142); L: Ladder; Lanes 1 and 3: wild-type homozygous alleles; Lanes 2 and 4: heterozygous alleles; Lane 5: variant homozygous alleles.

Characteristics of CAD patients and control subjects

The characteristics of patients and healthy subjects are demonstrated in Table 2. The two groups showed a significant difference in hypertension, hyperlipidemia and smoking $(\mathrm{P}<0.05)$.

Distribution of genotypes and alleles of HIF1 $\alpha$ and eNOS polymorphisms in patients $v s$. controls

Distribution of genotype polymorphisms did not indicate deviation from the Hardy-Weinberg equilibrium $(\mathrm{P}>0.05)$. The frequency distribution of genotypes for the patient and control groups for 4 polymorphisms was compared in Table 3.

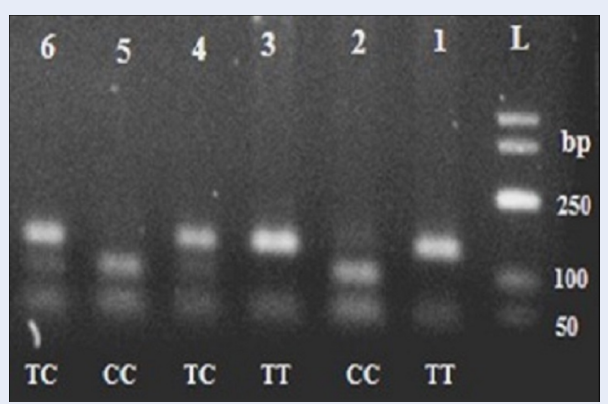

Figure 2: Analysis of polymorphism in eNOS genes using PCR followed by specific restriction enzyme digestion. SNP of eNOS T786C. Lanes 1 and 3: wild-type homozygous alleles; Lanes 4 and 6: heterozygous alleles; Lanes 2 and 5: variant homozygous alleles.

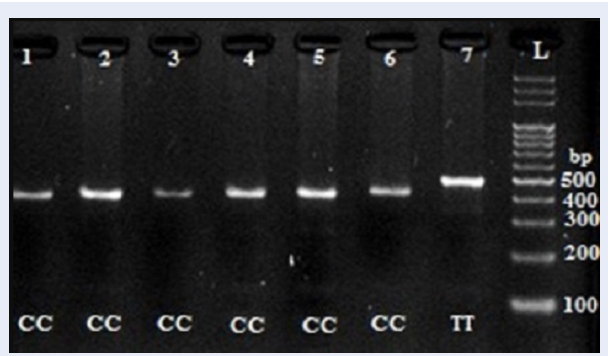

Figure 3: Analysis of polymorphism in HIF-1a using PCR followed by specific restriction enzyme digestion. SNP of HIF-1a p.T4181 (rs41508050); Lanes 1-6: wild-type homozygous alleles; Lane 7: variant homozygous alleles.

No significant difference was observed between the two groups for the 4 polymorphisms in terms of genotype and allele frequencies (all were $\mathrm{P}>0.05$ ). Frequency comparison of $\mathrm{C}>\mathrm{T}$ (rs10873142) polymorphism genotype of HIF $1 \alpha$ gene in the two groups showed that the frequency of TC genotype was $47 \%$ and $51.8 \%$ in patients and controls, respectively. The CC genotype had the lowest frequency in patients (8\%) and controls (9.1\%), but the difference in frequency distribution of $\mathrm{C}>\mathrm{T}$ ( $\mathrm{rs} 10873142)$ genotype in the two groups was not statistically significant.

The frequency of CC, TC and TT genotypes in p.T4181 (rs 41508050) polymorphism was 136 (98.55\%) and 0 (0\%), $2(1.44 \%)$ and $113(98.25 \%)$, and $1(0.87 \%)$ and $1(0.87 \%)$ in patient and control groups, respectively, for the genotypes. The difference in frequency distribution of p.T418I (rs41508050) genotypes in the two groups (patient and control) was not statistically significant. 
(5)

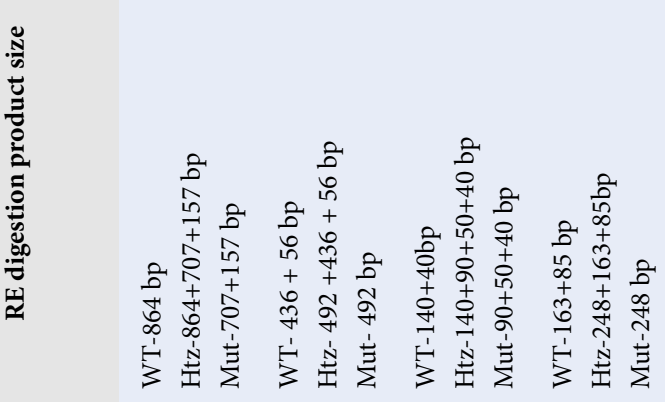

苍芯芯

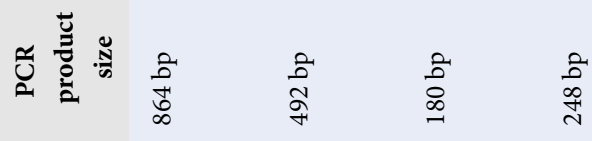
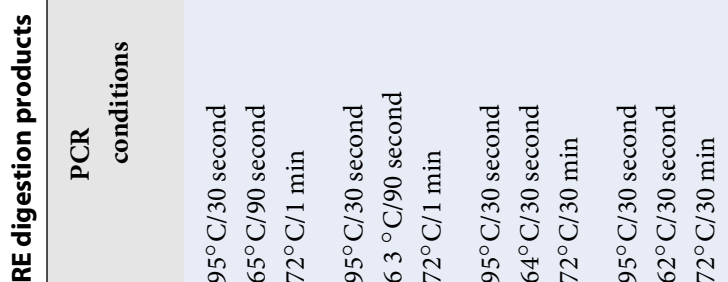

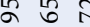

in 20
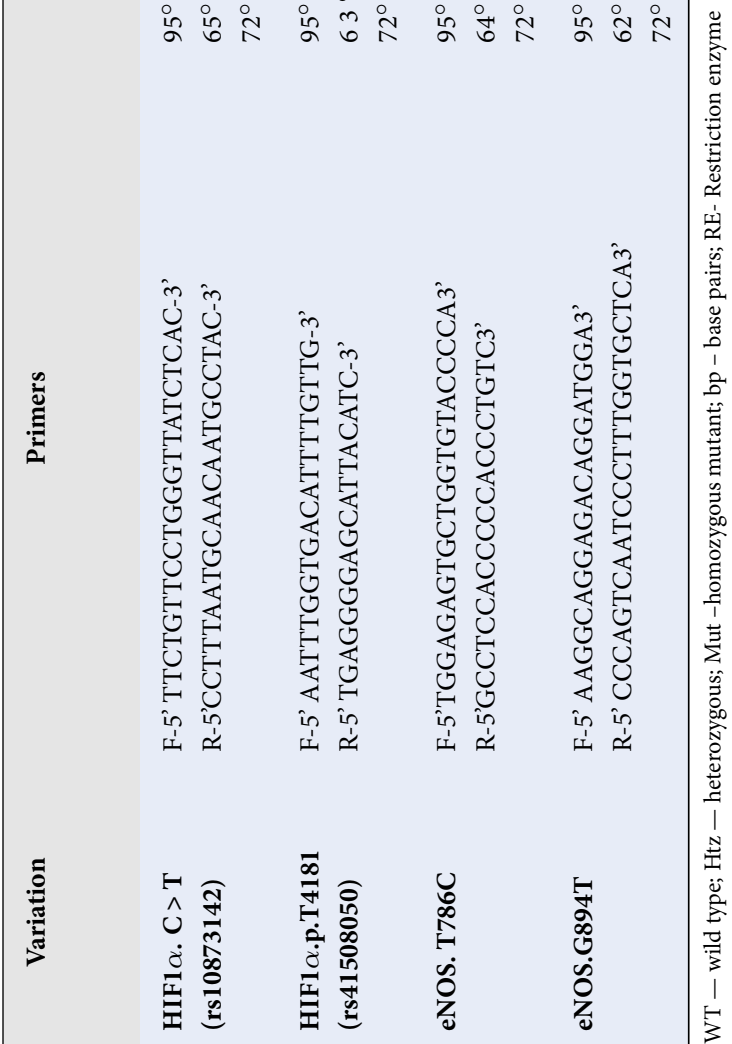
Table 2: Characteristics of CAD patients and control subjects

\begin{tabular}{lccc}
\hline & CAD, $\mathbf{n}$ & Controls, $\mathbf{n}$ & P-value \\
\hline Sex (Male/Female) & $65 / 73$ & $55 / 60$ & 0.90 \\
\hline Age (Years) & $61.53( \pm 10.43)$ & $54.33( \pm 13.41)$ & 0.055 \\
\hline Weight (Kg) & $71.20( \pm 16.41)$ & $70.00( \pm 10.59)$ & 0.62 \\
\hline $\begin{array}{l}\text { Hypertension (Yes/No) } \\
(>\mathbf{1 4 0} / \mathbf{9 0})\end{array}$ & $81 / 57$ & $33 / 82$ & $<0.001$ \\
\hline Hyperlipidemia (Yes/No)) & $57 / 81$ & $22 / 93$ & $<0.001$ \\
\hline $\begin{array}{l}\text { Diabetes mellitus (Yes/No) } \\
(\text { Glucose of }>\mathbf{1 2 0} \text { mg/dL) }\end{array}$ & $19 / 119$ & $8 / 107$ & 0.081 \\
\hline Smokers (Yes/No) & $36 / 102$ & $14 / 100$ & 0.006 \\
\hline CAD Heredity (Yes/No) & $37 / 101$ & $33 / 82$ & 0.73 \\
\hline
\end{tabular}

Table 3: Genotype and allele frequency in CAD patients and control subjects

\begin{tabular}{|c|c|c|c|c|c|c|}
\hline & Genotype & CAD n (\%) & Controls n (\%) & OR & CI 95\% & P-value \\
\hline \multirow{3}{*}{$\begin{array}{c}\mathrm{C}>\mathrm{T} \\
(\mathrm{rs} 10873142)\end{array}$} & TT (wt/wt) & $58(43.9)$ & $45(40.2)$ & & & Ref \\
\hline & TC (wt/mut) & $62(47)$ & $58(51.8)$ & 0.82 & $(0.48-1.40)$ & 0.48 \\
\hline & CC (mut/mut) & $12(9.1)$ & $9(8)$ & 1.03 & $(0.40-2.66)$ & 1 \\
\hline \multirow[t]{2}{*}{ Alleles } & $\mathrm{T}$ & $178(67.4)$ & $148(66.1)$ & & & Ref \\
\hline & $\mathrm{C}$ & $86(32.6)$ & $76(33.9)$ & 0.94 & $(0.64-1.37)$ & 0.75 \\
\hline \multirow{3}{*}{$\begin{array}{l}\text { p.T } 4181 \\
\text { (rs41508050) }\end{array}$} & $\mathrm{CC}$ (wt/wt) & $136(98.55)$ & $113(98.25)$ & & & Ref \\
\hline & CT (wt/mut) & 0 & . & - & - & - \\
\hline & $\mathrm{TT}$ (mut/mut) & $2(1.44)$ & $2(1.74)$ & 0.83 & $(0.11-6.00)$ & 1 \\
\hline \multirow[t]{2}{*}{ Alleles } & $\mathrm{C}$ & $272(98.55)$ & $226(98.7)$ & & & Ref \\
\hline & $\mathrm{T}$ & $4(1.45)$ & $4(1.3)$ & 1.11 & $(0.24-5.02)$ & 1 \\
\hline \multirow[t]{3}{*}{ T786C } & TT (wt/wt) & $74(54)$ & $57(50)$ & & & Ref \\
\hline & TC (wt/mut) & $55(40.1)$ & $47(41.2)$ & 0.90 & $(0.53-1.51)$ & 0.69 \\
\hline & CC (mut/mut) & $8(5.8)$ & $10(8.8)$ & 0.61 & $(0.22-1.66)$ & 0.33 \\
\hline \multirow[t]{2}{*}{ Alleles } & $\mathrm{T}$ & $203(74.08)$ & $161(70.61)$ & & & Ref \\
\hline & $\mathrm{C}$ & $71(25.91)$ & $67(29.38)$ & 0.84 & $(0.56-1.24)$ & 0.38 \\
\hline \multirow[t]{3}{*}{ G894T } & GG (wt/wt) & $74(59.2)$ & $57(52.3)$ & & & Ref \\
\hline & GT (wt/mut) & $40(32)$ & $39(35.8)$ & 0.79 & $(0.45-1.38)$ & 0.40 \\
\hline & TT (mut/mut) & $11(8.8)$ & $13(11.9)$ & 0.65 & $(0.27-1.56)$ & 0.33 \\
\hline \multirow[t]{2}{*}{ Alleles } & G & $188(75.20)$ & $153(70.18)$ & & & Ref \\
\hline & $\mathrm{T}$ & $62(24.80)$ & $65(29.82)$ & 0.77 & $(0.51-1.16)$ & 0.22 \\
\hline
\end{tabular}

OR: odd's ratio; CI: confidence interval; wt: wild-type allele forinvestigated polymorphism; mut: mutant allele 


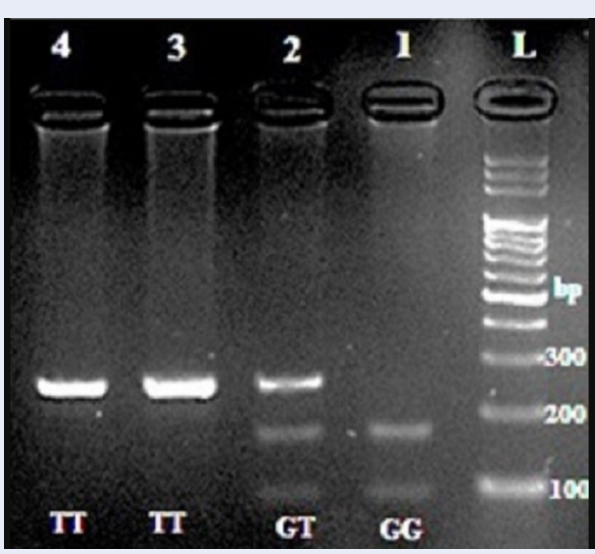

Figure 4: Analysis of polymorphism in eNOS genes using PCR followed by specific restriction enzyme digestion. SNP of eNOS G894T. Lane 1: wild-type homozygous alleles; Lane 2: heterozygous alleles; Lanes 3 and 4: variant homozygous alleles.

The frequency of TT, TC and CC genotypes in the T786C polymorphism in patient group was 74 (54\%) and $55(40.1 \%), 8(5.8 \%)$; whereas in control group it was 57(50\%), 47 (41.2\%) and 10 (8.80\%), respectively. The comparison of frequency of T786C genotypes between patient and control groups revealed that the TT genotype had the highest frequency (54\% and 50\%, respectively), while CC genotype had the lowest frequency in patient and control groups (54\% and 50\%, respectively). However, the difference in frequency distribution of T786C genotypes in the two groups was not statistically significant $(\mathrm{P}>0.05)$.

The frequency of GG, GT and TT genotypes in G894 polymorphism in patient group was 74 (59.2\%), 40 (32\%), $11(8.8 \%)$; while it was 57(52.3\%), 39 (35.8\%) and $13(11.9 \%)$ control group, respectively.

Frequency comparison of G894 genotypes in patient and control groups showed that GG genotype had the highest frequency (59.2\% and 52.3\%, respectively) and TT genotype had the lowest frequency in patient and control groups ( $8.8 \%$ and $11.9 \%$, respectively), but the difference in frequency distribution of G894T genotypes between the two groups was not statistically significant (Table 3 ).

Effects of T786C and G894T polymorphisms of eNOS on serum NO concentration

The difference in mean NO levels between healthy subjects and patients with different genotypes of T786C polymorphism was statistically significant $(\mathrm{P}=0.001)$, such that the highest and lowest NO levels were observed in individuals with TT and TC genotype, respectively (Table 4). Moreover, the difference in mean serum NO levels for the genotypes of G894T polymorphism in patients and controls was not statistically significant.

Mean serum NO and PON1 concentration in case and control groups

The mean difference in serum NO levels between patients $\left(1.48 \pm 0.19 \times 10^{2} \mu \mathrm{mol} / \mathrm{L}\right)$ and controls $(1.41$ $\left.\pm 0.12 \times 10^{2} \mu \mathrm{mol} / \mathrm{L}\right)$ was statistically significant $(\mathrm{P}=0.002)$; NO level was higher in the patient group than control. Mean serum concentration of PON1 enzyme was lower in patients $(17.89 \pm 13.97 \mathrm{nmol} / \mathrm{L})$ than in the controls $(21.23 \pm 13.83 \mathrm{nmol} / \mathrm{L})$, but the difference was not statistically significant $(\mathrm{P}=0.272)$.

\section{DISCUSSION}

$\mathrm{CAD}$ is a multi-factorial disease of which several genetic and environmental factors, as well as ethnic susceptibility, are involved in its development ${ }^{1,2}$. Understanding the genetic factors involved in susceptibility to a disease results in better treatment options for the disease ${ }^{16}$. In this study, no significant association was found between $\mathrm{C}>\mathrm{T}(\mathrm{rs} 10873142)$ and p.T4181 (rs41508050) polymorphisms of the HIF-1 $\alpha$ gene with CAD. Different results have been reported in the study of association between HIF $1 \alpha$ polymorphisms and cardiovascular diseases. There have been correlations reported for rs10873142, rs41508050 and rs11549465 polymorphisms with cardiovascular diseases, such as ischemic heart disease, CAD with stable exertional angina, and acute myocardial infraction ${ }^{17}$. However, no association was found for rs2057482, rs11549467 and rs 11549465 polymorphisms with these diseases ${ }^{18}$.

The findings of other studies on the relationship between eNOS gene polymorphisms and CAD are not consistent. For instance, in 1998, Hibi et al. pointed out, for the first time, the relationship between NO synthase gene polymorphism and myocardial infarction ${ }^{19}$. Results from a study by Nakayama et al. suggests that the CC variant in T786C polymorphism reduces eNOs synthesis and predisposes the patients to coronary spasms ${ }^{20}$. A study on Caucasian population showed that the $\mathrm{C}$ allele is associated with increased risk of multivessel CAD ${ }^{21}$. Tangurek et al. also found a significant difference in the distribution of T786C genotypes between patients and healthy subjects ${ }^{22}$. However; similar to results of Granath et al. ${ }^{23}$ and Ciftci et al. ${ }^{24}$, we found no significant difference in the frequency of T786C genotypes between CAD patients and those in the control group.

Furthermore, the frequencies of the T786C polymorphism genotypes in healthy subjects and patient groups were similar, but in general, a slight increase 


\begin{tabular}{|c|c|c|c|c|}
\hline T786C & TT & TC & $\mathrm{CC}$ & p-value \\
\hline $\begin{array}{l}\text { Cases. Nitric oxide } \\
\qquad(\mathrm{NO}) \\
\left(\times 10^{2} \mu \mathrm{mol} / \mathrm{L}\right)\end{array}$ & $0.16 \pm 1.55$ & $0.21 \pm 1.38$ & $0.12 \pm 1.49$ & 0.001 \\
\hline $\begin{array}{l}\text { Controls. Nitric } \\
\text { oxide }(\mathrm{NO}) \\
\left(\times 10^{2} \mu \mathrm{mol} / \mathrm{L}\right)\end{array}$ & $0.11 \pm 1.47$ & $0.110 \pm 1.34$ & $0.09 \pm 1.41$ & 0.001 \\
\hline G894T & GG & GT & TT & p-value \\
\hline $\begin{array}{l}\text { Cases. Nitric oxide } \\
\qquad(\mathrm{NO}) \\
\left(\times 10^{2} \mu \mathrm{mol} / \mathrm{L}\right)\end{array}$ & $0.18 \pm 1.49$ & $0.19 \pm 1.48$ & $0.17 \pm 1.39$ & 0.28 \\
\hline $\begin{array}{l}\text { Controls. Nitric } \\
\text { oxide (NO) } \\
\left(\times 10^{2} \mu \mathrm{mol} / \mathrm{L}\right)\end{array}$ & $0.13 \pm 1.40$ & $0.13 \pm 1.43$ & $0.10 \pm 1.40$ & 0.48 \\
\hline
\end{tabular}

in the frequency of wild TT genotype was observed in patients. In a study in Iran, a significant increase in $\mathrm{T}$ mutant frequency was reported in patients compared to controls ${ }^{25}$.

In our study of the G894T polymorphism, genotypes frequency was similar in healthy subjects and patients but, in general, a slight increase was seen in the frequency of wild GG genotype in patients. In general, few studies have been conducted on the relationship between eNOS gene polymorphisms and NO serum levels. In a study in UK evaluating the effect of G894T, T786C, VNTR intron 4 and A922G polymorphisms on NO production, it was concluded that none of these polymorphisms affect the plasma NO production $^{26}$. Similar to our study, in a study in Turkey, a correlation between CAD and T mutant allele in the G894T polymorphism, as well as serum levels of NO, was not confirmed ${ }^{27}$. Unlike our study, Yoon et al. reported increased serum levels of NO in control subjects bearing G894T mutation ${ }^{28}$.

In some studies, it has been reported that the T786C polymorphism does not affect plasma NO concentrations. Meanwhile in other studies, the association between reduced $\mathrm{NO}$ concentration in blood circulation and the presence of eNO-specific haplotypes bearing C (T786C) and G (G894T) alleles have been mentioned.

In our study, the difference in mean NO levels in the different genotypes of T786C gene was statistically significant $(\mathrm{P}<0.05)$ in both healthy subjects and patients, in such a way that maximum and minimum NO level was observed in individuals with TT and TC genotypes, respectively. In general, NO serum level was lower in individuals with mutant $\mathrm{C}$ alleles (heterozygotes and mutant homozygotes) than those with wild homozygous alleles. The results of correlation between serum levels of $\mathrm{NO}$ and CAD are different (similar to results of gene distribution and frequency of polymorphisms). In this study, we saw a significant increase in mean serum levels of NO in CAD patients $\left(1.48 \times 10^{2} \pm 0.19 \mu \mathrm{mol} / \mathrm{L}\right)$ compared to healthy controls $\left(1.41 \times 10^{2} \pm 0.12 \mu \mathrm{mol} / \mathrm{L}\right)$.

NO plays an important role in atherogenesis, and atherosclerosis has been associated with decreased endothelial NO production. In these pathological conditions, the expression of eNOS may be increased and result in increased NO levels. These findings suggest that an increase in serum levels of NO in CAD patients can play a compensatory role for the resumption of endothelial vasomotor function ${ }^{24-28}$.

Increased oxidative stress or reduced antioxidant defense mechanisms may be involved in the onset and progression of atherosclerosis. In some studies, the relationship between reduced levels of PON1 with CAD has been mentioned, but Rahmani and Azizi (in separate studies on Iranian population) have reported no significant differences in PON1 activity in patients and controls ${ }^{29-31}$. In our study, although serum levels of PON1 in the patient group were lower than the control group, no significant difference was found in serum PON1 levels between the two groups.

Moreover, we found no correlation between the frequency of genotypes and mutant alleles of T786C and G894T polymorphisms with CAD. Likewise, no correlation was found between G894T genotypes and serum NO levels in both groups. However, the difference of mean serum NO levels in T786C polymorphism in different genotypes was significant in both control and patient groups. In general, serum NO levels in individuals with mutant $\mathrm{C}$ allele (heterozygotes 
and homozygous mutants) were lower than individuals with wild-type homozygous allele.

\section{CONCLUSIONS}

Our results show that serum NO levels are relatively low in mutant $\mathrm{C}$ allele in T786C polymorphisms. As previously mentioned, inconclusive results suggest a correlation between NO gene polymorphisms, as well as NO serum levels, with cardiovascular disease. One possible explanation for these conflicting results could be that such studies usually concentrate on only one polymorphism in certain clinical conditions and the average impact may not be identified. Ethnic differences and the size of population under study can also impact inconsistent results from different studies.

To reinforce our understanding of the contribution of gene polymorphisms explored in this study and also to achieve any potential clinical relevance in terms of prognosis or therapeutic intervention for CAD patients, similar studies on these genes in different and larger populations are necessary.

\section{COMPETING INTERESTS}

The authors declare no conflict of interest.

\section{AUTHORS' CONTRIBUTIONS}

Ali Asghar Kiani: conceived of the presented idea and developed the theory and performed the computations; Vahide Heydari Nazarabad: carried out the experiment; Kolsum Ahmadi: carried out the experimen ; Khatereh Anbari: verified the analytical methods; Babak Baharvand Ahmadi: supervised the findings of this work. All authors discussed the results and contributed to the final manuscript.

\section{ACKNOWLEDGMENTS}

The project was sponsored by Deputy Office for Research of the Lorestan University of Medical Sciences.

\section{DATA AVAILABILITY}

The data used to support the findings of this study are included within the article.

\section{REFERENCES}

1. Anderson JL, Carlquist JF, Horne BD, Hopkins PN. Progress in unraveling the genetics of coronary artery disease and myocardial infarction. Current Atherosclerosis Reports. 2007;9:179-86. Available from: DOI:10.1007/s11883-0070017-4.

2. Kessler T, Erdmann J, Schunkert H. Genetics of coronary artery disease and myocardial infarction-2013. Current Cardiology Reports. 2013;15:368. Available from: DOI:10.1007/s11886013-0368-0
3. Kiani AA, Mortazavi Y, Zeinali S, Shirkhani Y. The molecular analysis of beta-thalassemia mutations in Lorestan Province, Iran. Hemoglobin. 2007;31:343-9. Available from: Doi:10 1080/03630260701459382.

4. Moncada S, Palmer RM, Higgs EA. Nitric oxide: physiology, pathophysiology, and pharmacology. Pharmacological Reviews. 1991;43:109-42.

5. Tesauro $M$, Thompson WC, Rogliani $P$, Qi L, Chaudhary PP, Moss J. Intracellular processing of endothelial nitric oxide synthase isoforms associated with differences in severity of cardiopulmonary diseases: cleavage of proteins with aspartate vs. glutamate at position 298. Proceedings of the National Academy of Sciences of the United States of America. 2000;97:2832-5. Available from: DOI:10.1073/pnas.97.6.2832.

6. Colombo MG, Andreassi MG, Paradossi U, Botto N, Manfredi S, Masetti S. Evidence for association of a common variant of the endothelial nitric oxide synthase gene (Glu298->Asp polymorphism) to the presence, extent, and severity of coronary artery disease. Heart (British Cardiac Society). 2002;87:525-8. Available from: DOI:10.1136/heart.87.6.525.

7. Tsukada T, Yokoyama K, Arai T, Takemoto F, Hara S, Yamada A. Evidence of association of the ecNOS gene polymorphism with plasma NO metabolite levels in humans. Biochemical and Biophysical Research Communications. 1998;245:190-3. Available from: DOI:10.1006/bbrc.1998.8267.

8. López-Reyes A, Rodríguez-Pérez JM, Fernández-Torres J, Martínez-Rodríguez N , Pérez-Hernández N, Fuentes-Gómez AJ. The HIF1A rs2057482 polymorphism is associated with risk of developing premature coronary artery disease and with some metabolic and cardiovascular risk factors. The Genetics of Atherosclerotic Disease (GEA) Mexican Study. Experimental and Molecular Pathology. 2014;96:405-10. Available from: DOI:10.1016/j.yexmp.2014.04.010.

9. Chen SM, Li YG, Wang DM, Zhang GH, Tan CJ. Expression of heme oxygenase-1, hypoxia inducible factor-1alpha, and ubiquitin in peripheral inflammatory cells from patients with coronary heart disease. Clinical Chemistry and Laboratory Medicine. 2009:47:327-33. Available from: Doi:10.1515/cclm. 2009.073.

10. Prior SJ, Hagberg JM, Phares DA, Brown MD, Fairfull L, Ferrell $\mathrm{RE}$. Sequence variation in hypoxia-inducible factor 1alpha (HIF1A): association with maximal oxygen consumption. Physiological Genomics. 2003;15:20-6. Available from: DOI: 10.1152/physiolgenomics.00061.2003.

11. Coulet F, Nadaud S, Agrapart M, Soubrier F. Identification of hypoxia-response element in the human endothelial nitric oxide synthase gene promoter. The Journal of Biological Chemistry. 2003;278:46230-40. Available from: DOI:10.1074/ jbc.M305420200.

12. Mayer B, Hemmens B. Biosynthesis and action of nitric oxide in mammalian cells. Trends in Biochemical Sciences. 1997:22:477-81. Available from: Doi:10.1016/s0968-0004(97) 01147-x.

13. Miranda KM, Espey MG, Wink DA. A rapid, simple spectrophotometric method for simultaneous detection of nitrate and nitrite. Nitric Oxide. 2001:5:62-71. Available from: DOI:10.1006/ niox.2000.0319.

14. Konac E, Dogan I, Onen HI, Yurdakul AS, Ozturk C, Varol A et al. Genetic Variations in the Hypoxia-Inducible Factor$1 \$ \alpha \$$ Gene and Lung Cancer. Experimental Biology and Medicine. 2009;234(9):1109-1116. Available from: 10.3181/ 0902-RM-49.

15. Marroni AS, Metzger IF, Souza-Costa DC, Nagassaki S, Sandrim VC, Correa RX. Consistent interethnic differences in the distribution of clinically relevant endothelial nitric oxide synthase genetic polymorphisms. Nitric Oxide. 2005;12:177-82. Available from: DOI:10.1016/j.niox.2005.02.002.

16. Exner $M$, Minar $E$, Wagner $O$, Schillinger $M$. The role of heme oxygenase-1 promoter polymorphisms in human disease. Free Radical Biology \& Medicine. 2004:37:1097-104. Available from: DOI:10.1016/j.freeradbiomed.2004.07.008 
17. Zheng ZL, Hwang YH, Kim SK, Kim S, Son MJ, Ro H. Genetic polymorphisms of hypoxia-inducible factor-1 alpha and cardiovascular disease in hemodialysis patients. Nephron Clinical Practice. 2009;113:c104-11. Available from: Doi:10.1159/ 000228542.

18. Alidoosti M, Ghaedi M, Soleimani A, Bakhtiyari S, Rezvanfard $M$, Golkhu S. Study on the role of environmental parameters and HIF-1A gene polymorphism in coronary collateral formation among patients with ischemic heart disease. Clinical Biochemistry. 2011;44:1421-4. Available from: DOI:10.1016/ j.clinbiochem.2011.09.001.

19. Hibi K, Ishigami T, Tamura K, Mizushima S, Nyui N, Fujita T. Endothelial nitric oxide synthase gene polymorphism and acute myocardial infarction. Hypertension. 1998;32:521-6. Available from: Doi:10.1161/01.hyp.32.3.521.

20. Nakayama M, Yasue $H$, Yoshimura M, Shimasaki Y, Kugiyama K, Ogawa H. T-786 $\rightarrow$ C mutation in the $5^{\prime}$-flanking region of the endothelial nitric oxide synthase gene is associated with coronary spasm. Circulation. 1999;99:2864-70. Available from: Doi:10.1161/01.cir.99.22.2864.

21. Rossi GP, Cesari M, Zanchetta M, Colonna S, Maiolino G, Pedon $\mathrm{L}$. The T-786C endothelial nitric oxide synthase genotype is a novel risk factor for coronary artery disease in Caucasian patients of the GENICA study. Journal of the American College of Cardiology. 2003;41:930-7. Available from: Doi:10.1016/s0735-1097(02)03012-7.

22. Tangurek B, Ozer N, Sayar N, Terzi S, Yilmaz H, Dayi SU. The relationship between endothelial nitric oxide synthase gene polymorphism (T-786 C) and coronary artery disease in the Turkish population. Heart and Vessels. 2006;21:285-90. Available from: DOI:10.1007/s00380-005-0902-0.

23. Granath B, Taylor RR, van Bockxmeer FM, Mamotte CD. Lack of evidence for association between endothelial nitric oxide synthase gene polymorphisms and coronary artery disease in the Australian Caucasian population. Journal of Cardiovascular Risk. 2001;8:235-41. Available from: Doi:10.1177/ 174182670100800408 .
24. Ciftçi C, Melil S, Cebi Y, Ersöz M, Cağatay P, Kiliçgedik M. Association of endothelial nitric oxide synthase promoter region (T-786C) gene polymorphism with acute coronary syndrome and coronary heart disease. Lipids in Health and Disease. 2008;7:5. Available from: Doi:10.1186/1476-511x-7-5.

25. Mehrtashfar S, Khatir AE, Ebrahimi A. Association of enos 894 $\mathrm{g}>\mathrm{t}$ gene polymorphism and risk of coronary artery disease in iranian population. In: ASHG; 2014. .

26. Jeerooburkhan N, Jones LC, Bujac S, Cooper JA, Miller GJ, Vallance $P$. Genetic and environmental determinants of plasma nitrogen oxides and risk of ischemic heart disease. Hypertension. 2001;38:1054-61. Available from: DOI:10.1161/hy1101 092967.

27. Afrasyap L, Ozturk G. NO level and endothelial NO synthase gene polymorphism (Glu298Asp) in the patients with coronary artery disease from the Turkish population. Acta Biochimica et Biophysica Sinica. 2004;36:661-6. Available from: DOI:10.1093/abbs/36.10.661.

28. Yoon Y, Song J, Hong SH, Kim JQ. Plasma nitric oxide concentrations and nitric oxide synthase gene polymorphisms in coronary artery disease. Clinical Chemistry. 2000;46:1626-30.

29. Rahmani M, Raiszadeh F, Allahverdian S, Kiaii S, Navab M, Azizi F. Coronary artery disease is associated with the ratio of apolipoprotein A-I/B and serum concentration of apolipoprotein $B$, but not with paraoxonase enzyme activity in Iranian subjects. Atherosclerosis. 2002;162:381-9. Available from: Doi:10.1016/s0021-9150(01)00715-8.

30. Azizi F, Rahmani M, Raiszadeh F, Solati M, Navab M. Association of lipids, lipoproteins, apolipoproteins and paraoxonase enzyme activity with premature coronary artery disease. Coronary Artery Disease. 2002;13:9-16. Available from: Doi:10.1097/00019501-200202000-00002.

31. Soltanpour MS, Soheili Z, Pourfathollah AA, Samiei $S$ Meshkani R, Kiani AA, et al. The A1298C mutation in methylenetetrahydrofolate reductase gene and its association with idiopathic venous thrombosis in an Iranian population. Laboratory Medicine. 2011;42(4):213-216. Available from: 10.1309/LM5LWXCHVZY9RFOM.

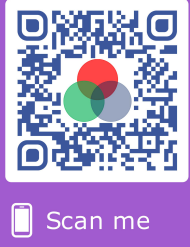

